\title{
Catalytic non-thermal plasma reactor for the decomposition of a mixture of volatile organic compounds
}

\author{
B RAMA RAJU, E LINGA REDDY, J KARUPPIAH, P MANOJ KUMAR REDDY \\ and CH SUBRAHMANYAM* \\ Energy and Environmental Research Laboratory, Department of Chemistry, Indian Institute of Technology, \\ Hyderabad 502 205, India \\ e-mail: csubbu@iith.ac.in
}

MS received 28 May 2012; revised 27 September 2012; accepted 11 October 2012

\begin{abstract}
The decomposition of mixture of selected volatile organic compounds (VOCs) has been studied in a catalytic non-thermal plasma dielectric barrier discharge reactor. The VOCs mixture consisting $n$-hexane, cyclo-hexane and $p$-xylene was chosen for the present study. The decomposition characteristics of mixture of VOCs by the DBD reactor with inner electrode modified with metal oxides of Mn and Co was studied. The results indicated that the order of the removal efficiency of VOCs followed as $p$-xylene $>$ cyclo-hexane $>n$ hexane. Among the catalytic study, MnOx/SMF (manganese oxide on sintered metal fibres electrode) shows better performance, probably due to the formation of active oxygen species by in situ decomposition of ozone on the catalyst surface. Water vapour further enhanced the performance due to the in situ formation of $\mathrm{OH}$ radicals.
\end{abstract}

Keywords. Non-thermal plasma; mixture of VOCs; ozone; $\mathrm{CO}_{2}$; oxidation.

\section{Introduction}

The emission of volatile organic compounds (VOCs) by various industrial and agricultural processes is a significant sources of air pollution and may cause problem to human health due to their toxicity (some of the VOC's are carcinogenic or responsible for respiratory diseases), hence has a negative impact on the environment. ${ }^{1-4}$ Some of the well-established technologies for VOC abatement are thermal and catalytic incineration, adsorption, condensation, bio-filtration, membrane separation or ultra-violet oxidation. ${ }^{5-9}$ These techniques may demand thermal energy in the range of $700-800^{\circ} \mathrm{C}$ (for thermal incineration) and $200-600^{\circ} \mathrm{C}$ (for catalytic oxidation). However, these techniques may not be effective and energetically expensive for the treatment of low VOC concentrations. In addition, the catalyst poisoning followed by deactivation represents a serious problem for these technologies. ${ }^{10}$ In this context non-thermal plasma (NTP) is an emerging technology for the removal of dilute concentrations of air pollutants. ${ }^{11,12}$ The major advantages of NTP technology include operation under ambient conditions, moderate capital cost, compact system, easy operations and short reaction time. ${ }^{13-17}$

*For correspondence
Dielectric barrier discharge (DBD) technique is one of the commonly used methods for producing electrical discharge plasma. The main principle of operation in NTP-DBD reactor is to apply energetic electric field between two electrodes that were separated by a barrier to generate primary electrons with high kinetic energy. ${ }^{14-17}$ These high energy electrons $(1-10 \mathrm{eV})$ may collide and excite the background gas $\left(\mathrm{O}_{2}\right.$ and $\left.\mathrm{N}_{2}\right)$ that lead to the formation of highly reactive species. ${ }^{18}$ The critical parameter in the use of this technique in pollution control devices is the energy cost to remove toxic molecules. The energy cost mainly depends on energy transfer from a power source to plasma reactor, configuration of electrodes and efficiency of chemical reactions. ${ }^{19}$ However, its application is greatly restricted by low energy efficiency and $\mathrm{CO}_{2}$ selectivity as well as suppression of undesirable by-products such as ozone. ${ }^{20-23}$ An attempt to overcome these limitations is to combine NTP with catalysts. ${ }^{4,23-25}$

The selected catalysts $(\mathrm{MnOx}$ and $\mathrm{CoOx})$ were known for ozone decomposition and several researchers reported the plasma catalytic effect of $\mathrm{MnOx}$ and $\mathrm{CoOx}$ for ozone decomposition. ${ }^{4,24,26-32}$ However, majority of these studies were dealt with single component VOCs. As industrial emission contain VOCs mixture, the present work focuses on the synergetic effect of DBD plasma with catalyst during the removal of mixture 
of VOCs. The inner electrode was made of sintered metal fibres (SMF) which acted as electrode as well as a catalyst after modification with transition metal (Mn or Co) oxides. A typical VOCs mixture consisting aliphatic compound ( $n$-hexane), alicyclic compound (cyclo-hexane) and aromatic compound ( $p$-xylene) was chosen to understand the influence of various parameters like input energy and water vapour on mitigation efficiency.

\section{Experimental}

The detailed schematic representation of the DBD reactor used in the present study was given elsewhere ${ }^{4}$ and the experimental set-up is illustrated in figure 1 . Briefly, the dielectric barrier discharge was generated in a cylindrical quartz tube with an inner diameter of $19.5 \mathrm{~mm}$. SMF (sintered metal fibres) made of $\mathrm{Fe}-\mathrm{Cr}$ alloy (in the form of cylindrical tube with a diameter of $12.5 \mathrm{~mm}$ ) was used as inner electrode after modification with transition metal oxides. Deposition of $5 \mathrm{wt} \%$ $\mathrm{MnOx}$ and CoOx on SMF was achieved by impregnation with metal nitrate solutions followed by drying and calcination at $773 \mathrm{~K}$ for $5 \mathrm{~h}$. One end of SMF filter was connected to AC high voltage through a stainless steel rod whereas the other end was connected to the gas stream outlet. Silver paste painted on the outer surface of the tube acted as an outer electrode. The discharge length was $10 \mathrm{~cm}$ and the discharge gap was fixed at $3.5 \mathrm{~mm}$. The AC high voltage in the range $14-22 \mathrm{kV}$ (peak-peak) with the frequency of $50 \mathrm{~Hz}$ was applied between the two electrodes. Conversion of mixture of VOC at each voltage was measured after $30 \mathrm{~min}$.

The mixture of VOCs was introduced through a motor driven syringe pump and mixed with ambient air (300 $\mathrm{ml} / \mathrm{min}$ at STP) in a mixing chamber. Air flow was regulated by pre-calibrated mass flow controllers (Aalborg, USA). The input concentration of total VOCs was fixed at $250 \mathrm{ppm}$ (hexane $=100 \mathrm{ppm}$, cyclohexane $=75 \mathrm{ppm}$ and $p$-xylene $=75 \mathrm{ppm}$ ) and was fed into the plasma reactor with a Teflon tube. Reactor outlet was connected to gas chromatography (Varian450) equipped with a flame ionization detector (FID) detector and a capillary column for monitoring VOC concentration. The formation of $\mathrm{CO}_{2}, \mathrm{CO}$ and $\mathrm{NO}_{\mathrm{x}}$ was simultaneously monitored with an infrared gas analyzer (Siemens Ultramat 22), whereas, ozone formed in the plasma reactor was measured with an UV absorption ozone monitor (API-450 NEMA). The global selectivity of $\mathrm{CO}_{2}, \mathrm{CO}$ and $\mathrm{CO}_{x}$ for represented as

$$
\begin{aligned}
& \text { Global selectivity of } \mathrm{CO}_{2} \%\left(\mathrm{~S}_{\mathrm{CO}_{2}}\right) \\
& \quad=\frac{\text { Total concentration of }\left[\mathrm{CO}_{2}\right]}{6(\text { Conv. of } n \text {-hexane })+6(\text { Conv. of cyclo-hexane })+8(p-\text { xylene })} \times 100 .
\end{aligned}
$$

Global Selectivity of $\mathrm{CO} \%\left(\mathrm{~S}_{\mathrm{CO}}\right)$

$$
=\frac{\text { Total concentration of }[\mathrm{CO}]}{6(\text { Conv. of } n \text {-hexane })+6(\text { Conv. of cyclo-hexane })+8(p-\text { xylene })} \times 100 \text {. }
$$

$$
\mathrm{S}_{\mathrm{CO}_{\mathrm{x}}}=\mathrm{S}_{\mathrm{CO}}+\mathrm{S}_{\mathrm{CO}_{2}} \text {. }
$$

The electrical power applied to the discharge in the DBD reactor was measured by using the V-Q Lissajous diagram, ${ }^{4}$ where the charge $\mathrm{Q}$ (i.e., time integrated current) was recorded by measuring the voltage across the capacitor $(\mathrm{C}=1 \mu \mathrm{F})$ connected in a series to the ground. Applied voltage was measured with a 1000:1 high voltage probe (Agilent 34136A) and the V-Q wave forms were monitored by a digital oscilloscope (Tektronix TDS 2014 B). The area of Lissajous figure characterizes the energy dissipated during the one period of voltage. Specific input energy
(SIE) of the discharge was calculated by following relation

$$
\mathrm{SIE}(\mathrm{J} / \mathrm{l})=\frac{\text { Power }(\mathrm{W})}{\text { gas flow rate }(1 / \mathrm{s})}
$$

Figure 2 shows that the energy (SIE) dissipated in the gas per pulse increases linearly with the applied voltage. Then one may suppose that a high electric field at the anode modifies electron mean energy, increases production of active species in the streamers, and then improves VOCs destruction and removal efficiency. ${ }^{18}$ 


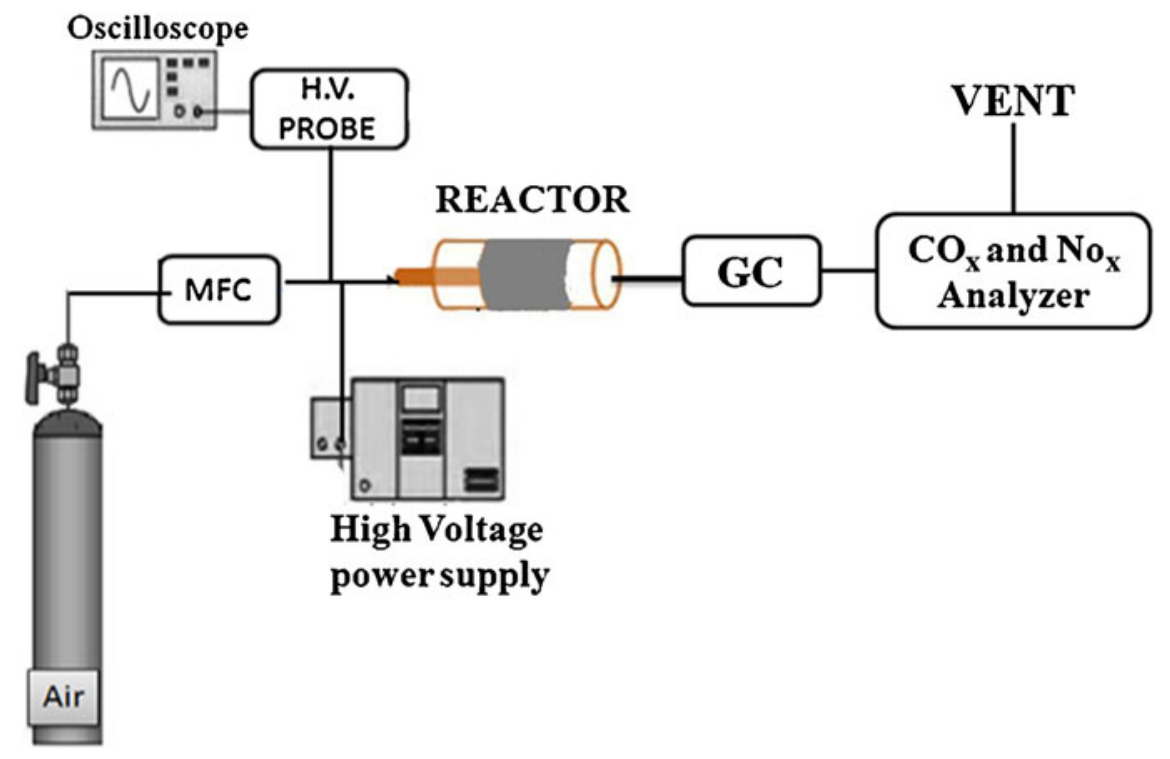

Figure 1. Schematic representation of experimental set-up.

\section{Results and discussion}

\subsection{Destruction of the mixture of VOCs in $D B D$ reactor}

The pollutant concentration at the inlet of the DBD reactor is fixed at $250 \mathrm{ppm}$. The carrier gas is either dry air or humid air (2.3 vol\% humidity was introduced by bubbling air through the water at $298 \mathrm{~K}$ ), at a flow rate of $300 \mathrm{ml} / \mathrm{min}$. The effect of the specific input energy on the VOCs decomposition with $\mathrm{SMF}, \mathrm{CoOx} / \mathrm{SMF}, \mathrm{MnOx} / \mathrm{SMF}$ and $\mathrm{MnOx} / \mathrm{SMF}$ with humid air was presented in figure 3 . This figure illustrates that the decomposition of VOCs increased

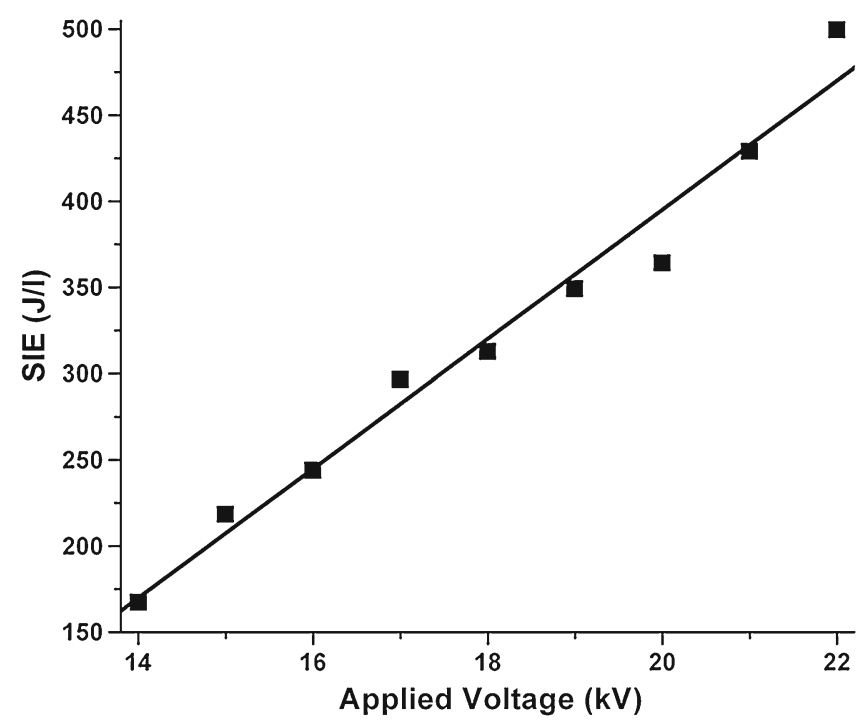

Figure 2. Variation of SIE as a function of voltage. with SIE and the concentration of $p$-xylene and cyclohexane were decreased from 75 to $0 \mathrm{ppm}$ at SIE of 350 and $425 \mathrm{~J} / 1$, respectively, whereas $n$-hexane was decreased from $100 \mathrm{ppm}$ to $0 \mathrm{ppm}$ at $500 \mathrm{~J} / 1$ when only pure SMF used as an inner electrode. While modified SMF (CoOx/SMF, MnOx/SMF) used as an inner electrode it showed better activity compared to pure SMF. $P$-xylene, cyclo-hexane and $n$-hexane were completely degradated at 300,350 and $365 \mathrm{~J} / 1$, respectively, when $\mathrm{CoOx} / \mathrm{SMF}$ as an inner electrode and 245, 310 and $350 \mathrm{~J} / 1$, respectively, when $\mathrm{MnOx} / \mathrm{SMF}$ used as an inner electrode. Here, SMF modified MnOx catalytic electrode showed better activity compare to other catalytic electrodes may be due to manganese oxide catalyst have better activity to transform the ozone to active oxygen species ${ }^{24,33}$ which were more reactive to

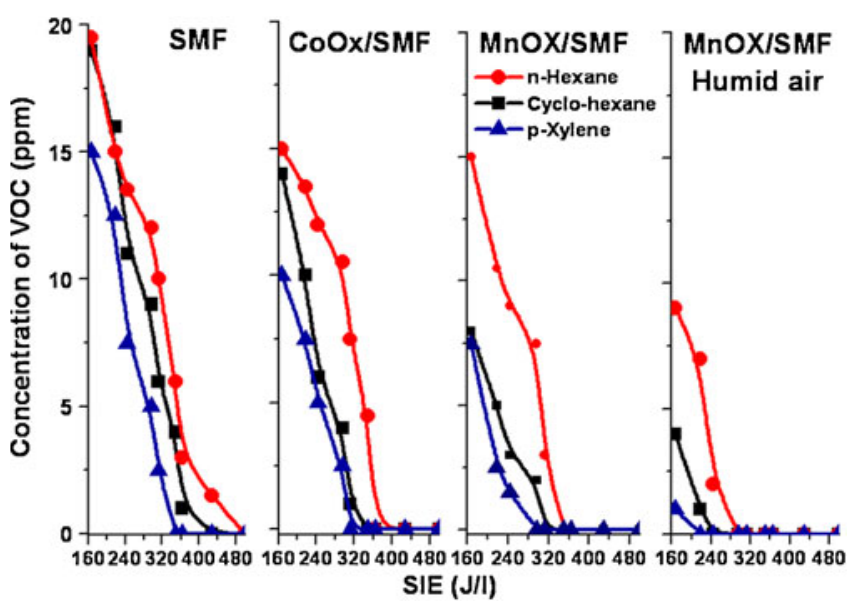

Figure 3. VOCs decomposition on different catalytic electrodes as a function of SIE. 
oxidize the organic components to $\mathrm{CO}_{2}$. $p$-xylene is the easiest compound to decompose and $n$-hexane is much more resistant to NTP treatment than the two other compounds in target VOCs present in the mixture. It showed that the order of removal efficiency of mixed VOCs followed $p$-xylene $>$ cyclo-hexane $>n$-hexane. This phenomenon could be explained by the competition and interaction of each component VOC molecule by high energy electrons $(6 \sim 10 \mathrm{eV})$ and active radicals $(\mathrm{O}, \mathrm{OH}, \mathrm{N})$ that may play an important role in the decomposition of gas pollutants. ${ }^{34}$ The chemical bond strength and molecule stability may also determine the removal rates of VOCs in the plasma process. ${ }^{35}$ Previous studies demonstrated that the removal efficiency of organic compound largely depends on its chemical structure. ${ }^{36-39}$ Among these VOCs, the bond energy of carbon-carbon bond is the strongest in $n$-hexane than cyclo-hexane, where as methyl group in $p$-xylene is comparatively unstable that can be broken easily.

The selectivity to gaseous products $\mathrm{CO}_{\mathrm{x}}\left(\mathrm{CO}+\mathrm{CO}_{2}\right)$ formed in the decomposition of mixture of VOCs is given in figure 4. As seen from figure 4, increasing SIE leads to higher selectivity and it is clearly observed that at $22 \mathrm{kV}$, for SMF as an inner electrode $45 \% \mathrm{CO}_{2}$ selectivity and 59 and $69 \%$ for CoOX/SMF, MnOx/SMF electrodes, respectively. With $\mathrm{CoOx}$ and $\mathrm{MnOx} / \mathrm{SMF}$ electrodes at low input energy, a significant increase in the selectivity to total oxidation products was achieved when compared to unmodified electrode. Within the plasma catalytic reactor, synergy was due to the utilization of the short-lived oxidizing species like oxygen

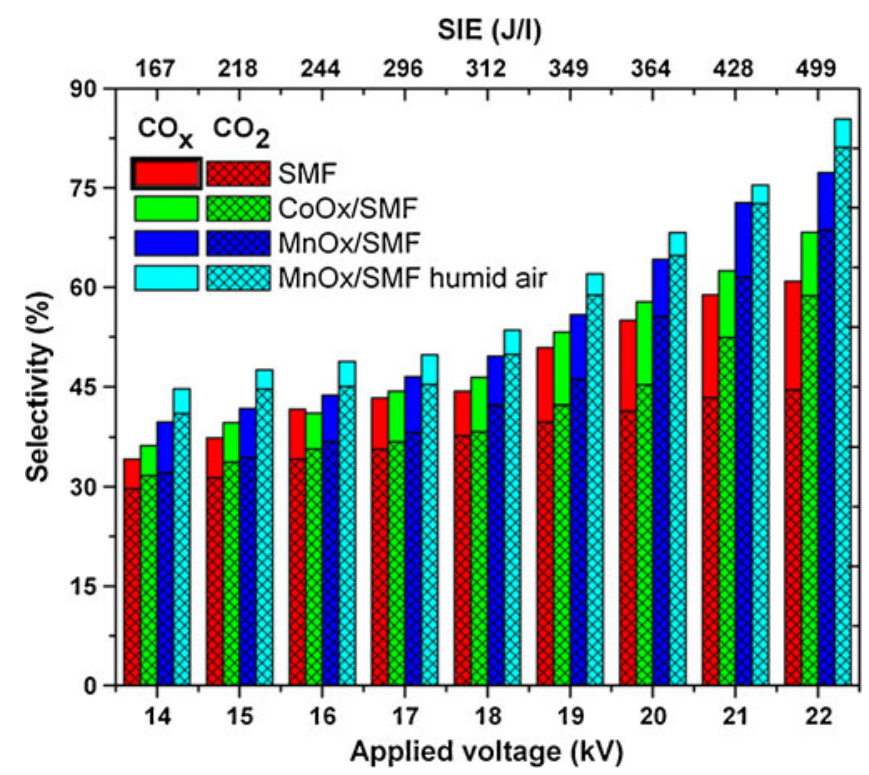

Figure 4. Selectivity of $\mathrm{CO}_{x}$ and $\mathrm{CO}_{2}$ with different catalytic electrode during the abatement of $250 \mathrm{ppm}$ mixture of VOC as a function of SIE and applied voltage. radical anion $\left(\mathrm{O}_{\mathrm{n}}^{-1}\right)$ and electronically activated oxygen molecule $\left(\mathrm{O}_{2}^{*}\right)$. The DBD reactor containing catalytic electrode, it is possible to overcome the limitations in-plasma reactor and avoiding the carbon deposition.

\subsection{Influence of water vapour}

Influence of water vapour on decomposition of mixture of VOCs was studied by SMF modified with MnOx electrode which showed better activity compared to remaining catalytic electrodes. The mixture of VOCs removal by DBD has been enhanced as a function of the presence of the water vapour (2-3 Vol \%) in air. For water vapour production, air was passing through the bubbler. It can be observed that mixture of VOCs removal by DBD in humid air is higher than that in dry air (figure 3), at the same value of the specific energy. From figure 3, it is observed that at 220, 245 and $295 \mathrm{~J} / 1$ SIE was sufficient for the complete decomposition of $P$-xylene, cyclo-hexane and $n$-hexane VOCs, respectively and figure 4 illustrates that $82 \% \mathrm{CO}_{2}$ selectivity was observed which was better than dry condition. In the presence of water vapour, the hydroxyl radical may be produced by dissociative electron collisions with $\mathrm{H}_{2} \mathrm{O}$ (Eq. 5) that may lead to a higher oxidation rate of VOCs for a given value of the specific energy. ${ }^{40,41}$ On the other hand, it also has an adverse effect on removal of target compounds due to electronegative characteristics. $^{41,42}$

$$
{ }^{*} \mathrm{e}^{-}+\mathrm{H}_{2} \mathrm{O} \rightarrow \cdot \mathrm{OH}+\cdot{ }^{\bullet}+\mathrm{e}^{-} .
$$

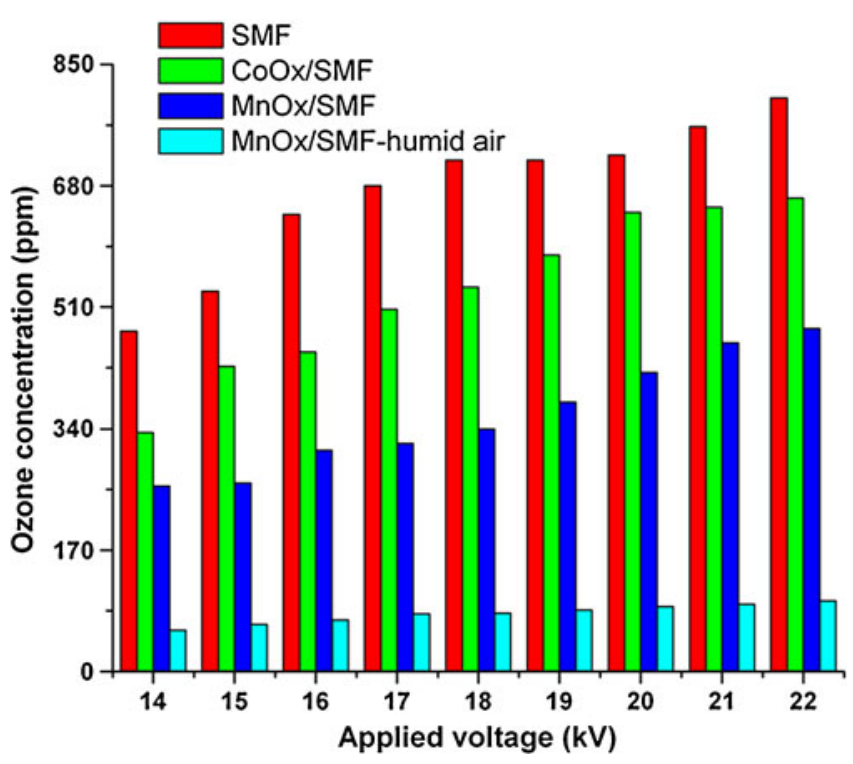

Figure 5. Ozone concentration variation with different catalytic electrodes as a function of applied voltage. 
It is well-known that $\mathrm{O}_{3}$ can be abundantly generated during the discharge in DBD reactor. ${ }^{4,24}$ However, its formation was suppressed due to the extinguishing of energetic electrons by water vapour. ${ }^{43}$ It can be found that the $\mathrm{O}_{3}$ concentration dropped in the presence of water vapour (figure 5). $\mathrm{O}_{3}$ is a strong oxidant and can be decomposed into $\mathrm{O}$, which is highly reactive and can efficiently oxidize the VOCs components. Thus, water vapour can impose negative effect on VOCs removal by inhibiting $\mathrm{O}_{3}$ formation and subsequent catalytic ozonation. However, the rate constants $\mathrm{O}$ and $\cdot \mathrm{OH}$ are much more active than $\mathrm{O}_{3}$ for decomposition of $\mathrm{VOCs}^{43}$ hence the decomposition rate of VOCs increases. Due to $\mathrm{OH}$ radicals and $\mathrm{O}$ species, the selectivity of $\mathrm{CO}_{2}$ also increases when compared to dry air.

\subsection{Formation of undesirable products}

In general, during the removal of VOCs, formation of undesirable products is one of the major problems. ${ }^{24}$ Some of these molecules are a source of olfactory pollution or environmental hazards. Therefore the byproducts identification and quantification is a key step to appreciate the viability of the plasma depollution process. The dissociation of air may lead to $\mathrm{N}$ and $\mathrm{O}$ production, which is the main precursor of $\mathrm{NO}_{\mathrm{x}}$. The formation of $\mathrm{NO}_{\mathrm{x}}$ occurs when the temperature of the gas is significantly increased by the plasma and reaches about $373 \mathrm{~K} .{ }^{23}$ However, no traces of nitrogen oxides such as $\mathrm{NO}$ and $\mathrm{NO}_{2}$ detected among the numerous byproducts. One of the applications of NTP is ozone generation. Large amounts of ozone are formed in the DBD plasma while VOCs are removed. Ozone formation occurs when following reactions take place between atomic oxygen and molecular oxygen.

$$
\begin{aligned}
& \mathrm{O}+\mathrm{O}_{2}+\mathrm{N}_{2} \rightarrow \mathrm{O}_{3}+\mathrm{N}_{2} . \\
& \mathrm{O}+\mathrm{O}_{2}+\mathrm{O}_{2} \rightarrow \mathrm{O}_{3}+\mathrm{O}_{2} .
\end{aligned}
$$

Ozone is a long-lived species and for both in-plasma and post-plasma catalytic reactors, it plays an important role during the oxidation of VOCs. However, the atomic oxygen formed due to in situ decomposition of ozone may effectively interact with partially oxygenated species only when catalyst placed in discharge zone. ${ }^{44}$ It is also interesting to note that $\sim 800 \mathrm{ppm}$ of $\mathrm{O}_{3}$ was observed when VOCs mixture decomposition on SMF electrode at $22 \mathrm{kV}$ that decreased to $\sim 660 \mathrm{ppm}$ with $\mathrm{CoOx} / \mathrm{SMF}$ and $\sim 480 \mathrm{ppm}$ with $\mathrm{MnOx} / \mathrm{SMF}$ and finally $<100 \mathrm{ppm} \mathrm{MnOx/SMF}$ in humid air condition, as shown in figure 5. As observed in figure 5, the best performance of the plasma reactor was achieved with catalytic MnOx/SMF electrode under humid air condition, which shifted the product distribution towards total oxidation, whereas conversion remains nearly the same on all the catalysts. These results suggest that the better performance of $\mathrm{MnOx} / \mathrm{SMF}$ electrode under dry condition may be due to the formation of atomic oxygen by in situ decomposition of ozone, ${ }^{33}$ whereas under humid conditions, it may be primarily due to oxidation by $\mathrm{OH}$ radicals.

\section{Conclusions}

The experimental results during the oxidation of low concentration of mixture of VOCs indicated that the removal efficiency of VOCs significantly enhanced in the presence of metal oxide catalysts, especially $\mathrm{MnOx} / \mathrm{SMF}$. The removal efficiency followed the order, $p$-xylene $>$ cyclo-hexane $>n$-hexane. Water vapour may facilitate the formation of strong oxidant hydroxyl radicals and active $\mathrm{O}$ species by in situ decomposition of ozone, hence high conversion and selectivity to total oxidation of VOCs.

\section{Acknowledgements}

Authors would like to thank the Council of Scientific and Industrial Research (CSIR), India for the financial support.

\section{References}

1. Monks P S, Granier C, Fuzzi S, Stohl A, Williams M L, Akimoto H, Amann M, Baklanov A, Baltensperger U, Bey I, Blake N, Blake R S, Carslawn K, Cooper O R, Dentener F, Fowler D, Fragkou E, Frost G J, Generoso S, Ginoux P, Grewet V, Guenther A, Hansson H C, Hennew S, Hjorth J, Hofzumahaus A, Huntrieser H, Isaksen I S A, Jenkin M E, Kaiser J, Kanakidou M, Klimont Z, Kulmala M, Laj P, Lawrence M G, Lee J D, Liousse C, Maione M, McFiggans G, Metzger A, Mieville A, Moussiopoulos N, Orlando J J, ODowd C D, Palmer P I, Parrish D D, Petzold A, Platt U, Poschl U, Prevot A S H, Reeves C E, Reimann S, Rudich Y, Sellegri K, Steinbrecher D, Simpson H, ten Brink J, Theloke G R, van der Werf R, Vautard V, Vestreng R, Vlachokostas C and von Glasow R 2009 Atmos. Environ. 435268

2. Atkinson R 2000 Atmos. Environ. 342063

3. Odum J R, Jungkamp T P W, Griffin R J, Forstner H J L, Flagan R C and Seinfeld J H 1997 Environ. Sci. Technol. 311890

4. Subrahmanyam C, Magureanu M, Renken A and Minsker-Kiwi L 2006 Appl. Catal. B: Environ. 65150

5. Choma J, Jaroniec M and Spikelet M 2007 Environ. Protec. 293 
6. Li W B and Gong H 2010 Acta Phys-Chim. Sin. 26 885

7. Kumar A, Dewulf J and Van Langenhove H 2008 Chem. Eng. J. 13682

8. Mudliar S, Giri B, Padoley K, Satpute D, Dixit R, Bhatt P, Pandey R, Juwarkar A and Vaidya A 2010 J. Environ. Manag. 911039

9. Demeestere K, Dewulf J and Van Langenhove H 2007 Crit. Rev. Environ. Sci. Technol. 37489

10. Than Quoc An H, Pham Huu T, Le Van T, Cormier J M and Khacef A 2011 Catal. Today 176474

11. Chang M B and Tseng T D 1996 J. Environ. Eng. 12241

12. Nunez C M, Ramsey G H, Ponder W H, Abbott J H, Hamel L E and Kariher P H 1993 Air Waste 43242

13. Mizuno A 2007 Plasma Phys. Contr. Fusion 49 A1

14. Kogelschatz U 2003 Plasma Chem. Plasma Processing 231

15. Kogelschatz U, Eliasson B and Egli W 1997 J. De Phys. IV 7 C4-47

16. Fridman A, Chirokov A and Gutsol A 2005 J. Phys. D: Appl. Phys. 38 R1

17. Fridman A 2008 Plasma chemistry. New York: Cambridge University Press

18. Jarrige J and Vervisch P 2006 J. Appl. Phys. 99 113303(1)

19. Khacef A, Cormier J M and Pouvesle J M 2006 Eur. Phys. J. Appl. Phys. 33195

20. Chen H L, Lee H M, Chen S H, Chang M B, Yu S J and Li S N 2009 Environ. Sci. Technol. 432216

21. Oda T 2003 J. Electrost. 57293

22. Delagrange S, Pinard L and Tatibouet J M 2006 Appl. Catal. B: Environ. 6892

23. Fan X, Zhu T, Wang M and Li X 2009 Chemosphere 75 1301

24. Subrahmanyam Ch, Renken A and Kiwi-Minsker L 2006 Appl. Catal. B: Environ. 65157

25. Kim H H, Oh S M, Ogata A and Futamura S 2005 Appl. Catal. B: Environ. 56213
26. Roland U, Holzer F and Kopinke F D 2005 Appl. Catal. B: Environ. $\mathbf{5 8} 217$

27. Roland U, Holzer F and Kopinke F D 2002 Catal. Today 73315

28. Ayrault C, Barrault J, Blin-Simiand N, Jorand F, Pasquiers S, Rousseau A and Tatibouet J M 2004 Catal. Today 8975

29. Einaga H and Ogata A 2009 J. Hazardous Mater. 164 1236

30. Karuppiah J, Karvembu R and Subrahmanyam Ch 2012 Chem. Eng. J. 18039

31. Karuppiah J, Sivachrandiran L, Karvembu R and Subrahmanyam Ch 2010 Chem. Eng. J. 165194

32. Karuppiah J, Sivachrandiran L, Karvembu R and Subrahmanyam Ch 2011 Chinese J. Catal. 32795

33. Futamura S, Einaga H, Kabashima H and Hwan L Y 2004 Catal. Today 8989

34. Ogata A, Shintani N, Mizuno A, Kushiyama S and Yamamoto T 1999 IEEE Trans. Ind. Appl. 35753

35. Wang H, Li D, Wu Y, Li J and Li G 2009 J. Electrost. 67 547

36. Mok Y S, Nam C M, Cho M H, Nam I S 2002 IEEE Trans. Plasma Sci. 30408

37. Yamamoto T 1997 J. Electrost. 42227

38. Ogata A, Ito D, Mizuno K, Kushiyama S, Gal A and Yamamoto T 2002 Appl. Catal. A: General 2369

39. Koutsospyros A D, Yin S M, Christodoulatos C and Becker K 2005 IEEE Trans. Plasma Sci. 3342

40. Bo Z, Yan J H, Li X D, Chi Y, Cen K F and Cheron B G 2007 Plasma Chem. Plasma Processing 27546

41. Guo Y F, Ye D Q, Chen K F and Tian Y F 2006 Plasma Chem. Plasma Processing 26237

42. Zhu T, Li J, Jin Y, Liang Y and Ma G 2008 Int. J. Environ. Sci. Technol. 5375

43. Huang H, Ye D and Leung D Y C 2011 IEEE Trans. Plasma Sci. 39576

44. Roland U, Holzer F, Poppl A and Kopinke F D 2005 Appl. Catal. B: Environmental 58227 